\title{
Other-repetition in conversation across languages: Bringing prosody into pragmatic typology
}

\author{
G I O V A N N I R O S I \\ University of California, Los Angeles, USA \\ University of Helsinki, Finland
}

\section{A B S T R A C T}

In this article, I introduce the aims and scope of a project examining other-repetition in natural conversation. This introduction provides the conceptual and methodological background for the five language-specific studies contained in this special issue, focussing on other-repetition in English, Finnish, French, Italian, and Swedish. Other-repetition is a recurrent conversational phenomenon in which a speaker repeats all or part of what another speaker has just said, typically in the next turn. Our project focusses particularly on other-repetitions that problematise what is being repeated and typically solicit a response. Previous research has shown that such repetitions can accomplish a range of conversational actions. But how do speakers of different languages distinguish these actions? In addressing this question, we put at centre stage the resources of prosody - the nonlexical acoustic-auditory features of speech — and bring its systematic analysis into the growing field of pragmatic typology- the comparative study of language use and conversational structure. (Repetition, conversation, prosody, pragmatics, typology)*

\section{R E P E T I T I O N}

Repetition is a basic operation that speakers of any language do in and on talk. Studied for centuries as a central ingredient of many rhetorical figures in argumentative, narrative, and poetic discourse, repetition is now understood as a pervasive feature of any form of language usage, and in fact of social and cultural life more generally (Brown 1999). Repetition plays a fundamental role in language usage from the early stages of development, supporting the transmission and acquisition of words, sounds, and syntactic structures (Keenan 1977; Bennett-Kastor 1994; Tarplee 1996; Brown 1998). Among adults, repetition is a resource for building cohesion into the fabric of discourse (Halliday \& Hasan 1976), for creating interpersonal involvement and affiliation (Tannen 1989), and for accomplishing many other functions ranging from agreeing to contradicting, from sharing humour to mocking (Norrick 1987), making it a central building block in the architecture of intersubjectivity (Sidnell 2014). 
Being such an important resource in language usage and social interaction and having been researched in various fields of linguistic and social science, the phenomenon of repetition can be approached in different ways. As such, we need to specify what kind of repetitions we are concerned with in what follows. First, our focus is on verbal repetition, that is, on the resaying of words, phrases, or clauses, to be distinguished from prosodic repetition that reproduces the suprasegmental features of previous speech (Couper-Kuhlen 1996:367). Second, we intend repetition as lexical replication, that is, as the resaying of the 'same' word, phrase, or clause. This specification is necessary as repetition may be conceptualised on a cline extending from exact replication at one extreme to paraphrase at the other. A large strand of the literature adopts a broad definition of repetition that includes the resaying of something with substantial rewording; the interest of this research is typically in the wider phenomenon of parallelism, echoing, and resonance (Tannen 1989; Johnstone 1994; Du Bois 2014). In the present project, we adopt a strict definition, by which repetition is intended as a 'near copy' of the original saying (Couper-Kuhlen 1996:368), involving the replication of its lexical material with only limited modification, such as deictic shifts (Schegloff 1996, 1997; Brown 1998). Third, repetition can be divided into two classes depending on whether it is done by the same speaker of the first saying - self-repetition - or by someone OTHER than the speaker of the first saying; our focus here is on the latter class: otherrepetition. Lastly, our object of study needs to be delimited in terms of sequential action. As already laid out by Schegloff (1996:177), other-repetitions can occupy at least three different types of sequential position, or better, enact three different types of sequential functions: initiating, responding, and third-position functions. Other-repetition may be used to initiate a sequence, such as a repair sequence aimed at clarifying a reference to a person (e.g. A: my cousin studied classics B: your cousin? A: Mary). ${ }^{1}$ Or it may be used responsively, for instance, to agree with an assessment (e.g. A: I remember she had a beautiful smile B: a beautiful smile [nodding]). Other-repetition may also enact a third-position action that serves to acknowledge receipt of a response, such as the answer to a question (e.g. A: were you classmates only in high school or? B: only in high school A: only in high school [nodding]). In the project reported on in this special issue, our focus is primarily on repetitions that initiate a sequence. This means, in the first place, other-initiations of repair and related actions. But we also consider repetitions embodying third-position actions as these, too, can occasion a response (see Schegloff 1997:527).

In summary, our object of study in this project is verbal repetition, intended as exact or modified replication of lexical material, produced by someone other than the speaker of the first saying, so as to problematise or otherwise engage with what has been said making a response conditionally or optionally relevant (more details in later sections).

These other-repetitions have been the topic of much research, in some of which they have been referred to as 'echo utterances' or 'echoes', including 'echo 
questions' and 'echo exclamations' (Bolinger 1957; Quirk, Greenbaum, Leech, \& Svartvik 1972:408-11). One of the reasons why such other-repetitions have fascinated generations of linguists and social scientists is that they can accomplish very different interactional work, ranging from seeking clarification to expressing surprise to questioning the acceptability of what is said, spanning many of the fundamental preoccupations of human interaction: mutual understanding, alignment, agreement, and affiliation. To distinguish among all of these functions, the lexical content of the repetition is generally of little help to the interlocutor, because it is after all what they have just said themselves. The replication of words per se does little more than tie back to the original saying. So, in otherrepetition sequences, speakers and recipients need to resort to other cues, such as prosody and visible behaviour, in order to determine what the repetition is doing and how to respond to it.

But other-repetitions are not only a linguistic and interactional phenomenon in their own right; they also provide for a sequentially and formally delimited environment that is an especially good locus for cross-linguistic comparison. Repeating what another has just said is an operation that is available in any language, as it largely does not depend on language-specific forms. At the same time, other-repetition is never mere reduplication of what has been said: it always requires the speaker to modulate or frame the resaying in some fashion (Sidnell 2009:5-7). As such, otherrepetition involves the mobilisation of the local resources of a language, including different grammatical, prosodic, and gestural systems, which have consequences for how the actions accomplished by other-repetitions are marked and distinguished.

In the next two sections, I first elaborate on the topic of cross-linguistic comparison with a presentation of the field of pragmatic typology and then focus in on the study and comparison of prosody.

\section{PRA G M A T I C T Y POLOGY}

The field of pragmatic typology combines two areas of linguistic science: pragmatics - the study of language in context and of the rules that govern its useand typology - the comparative study of linguistic systems (phonological, morphological, syntactic, semantic) to determine how and to what extent their organisation is similar or different across languages. Pragmatic typology unites the goals and tools of pragmatics and typology to investigate patterns of language use and conversation across different communities, in order to establish similarities grounded in the common infrastructure of human interaction as well as differences driven by the local resources of particular linguistic and cultural settings (see also Sidnell 2009; Dingemanse \& Enfield 2015, among others).

The roots of this growing field go a long way back and can be traced to early efforts of linguists, anthropologists, and sociologists (Dingemanse \& Floyd 2014). One of the most important landmarks in this field is the work done by Brown \& Levinson (1987) as part of their theory of politeness. The development 
of the theory was spurred by the observation of strong similarities in the design of speech acts in three unrelated languages and cultures (Tamil, Tzeltal, and English). This suggested the existence of common universal pressures affecting people's linguistic and social behaviour, which the theory of politeness was designed to explain. The theory partially influenced the development of a prolific area of research commonly known as 'cross-cultural pragmatics', the specific aim of which was to establish similarities and differences in the realisation of speech acts (e.g. requests, apologies) across languages and cultures, by following a common set of procedures based on written elicitation in the form of a 'discourse completion task' (Blum-Kulka, House, \& Kasper 1989).

The comparative study of language use has greatly developed since the inception of politeness theory and the booming days of cross-cultural pragmatics. In a nutshell, the latest research in this area can be characterised by two main elements. The first is a commitment to the empirical analysis of recordings of natural conversation - the central arena of language use-increasingly informed by the framework of conversation analysis. This creates a substantial overlap between pragmatic typology and what can be referred to as comparative conversation analysis (see Sidnell 2009). The second element is a methodology for making comparison systematic. This normally requires us to identify a formally and sequentially delimited environment, establish clear parameters for linguistic and interactional variation, and it increasingly involves coding schemes that both aid in the formulation of comparative aims and enable quantitative analysis of linguistic and interactional features.

A prerequisite for research in any area of linguistic typology is the ability to compare like with like (Greenberg 1966; Croft 2003; Dingemanse \& Enfield 2015 , among others). This means being able to draw the contours of the target phenomenon so that the categories under comparison and the environment in which they operate are commensurable. Just as in the study of the sound inventories that different languages have for constructing words (phonological typology) or in the study of the vocabularies they have for referring to parts of the body (semantic typology), in pragmatic typology as well, we must be able to properly define the environment in which a pragmatic phenomenon occurs and the categories of talk and other conduct that operate in it. To take the definition of the environment first, in the framework of conversation analysis this is achieved not by constraining the actions of speakers by means of experimental design, but by identifying a conversational structure, a formally and sequentially delimited exchange of actions that is recurrent and stable across topics, speakers, settings, languages, and cultures (see Stivers et al. 2009; Dingemanse \& Floyd 2014). As discussed in the previous section, other-repetition sequences provide just such an environment. As for the categories under comparison, these will concern both the linguistic practices operating within the environment and the distinct interactional patterns they give rise to. The articulation of such categories, too, must be sensitive to cross-linguistic applicability. To achieve this, typologists make an essential distinction between 
language-particular descriptive categories, which are based on the internal organisation of a given language, and language-independent comparative categories, or better 'comparative concepts' (Haspelmath 2010), which are designed to capture generic patterns that cut across language-particular categories. This distinction allows us to juxtapose linguistic objects that are not equivalent when considered in their respective systems but that are sufficiently similar in a relevant respect. As a linguistic object, other-repetition is relatively straightforward to capture crosslinguistically as it is largely independent of language-particular morphosyntax and lexicon. ${ }^{2}$ However, some of the formal parameters along which other-repetitions can be analysed do require us to use comparative concepts. For example, to analyse the grammatical function of a repeated word, we cannot use lexical categories such as adjective or adverb, because the criteria for assigning words to these categories are not the same across languages. However, we can use the concept of modification (as opposed to reference and predication) to capture words whose main function is to specify a property or quality of an entity or the manner of an action (see Croft 2003:183-88). As another example, particles such as English $o h$, Finnish $a i$, and French $a h$ are not equivalent in the range of meanings and uses they can have. When considered as prefaces to an other-repetition, however, these particles can all occupy the same turn-initial position to signal a 'change of state' of the speaker (Heritage 1984). So, in this structural position, these particles are sufficiently similar for comparison. Finally, comparative concepts are necessary also in the domain of prosody. As is well known, the prosody of languages varies greatly, one area of particular variation being the intonation system (Hirst \& Di Cristo 1998). As an example, take a RISE-FALL contour, which is available in both French and Italian. Even if the contour is melodically similar in the two languages, its typical function in other-repetition sequences could not be more different: challenging in French, seeking confirmation in Italian (Persson, this issue; Rossi, this issue). As a descriptive category, therefore, the use of a RISE-FALL contour is not commensurable beyond its surface similarity (see also Dingemanse \& Enfield 2015:104). To compare intonation contours pragmatically, we must resort to comparative concepts that are grounded in the oppositional relations between them, formulated by reference to the functions that the contours are typically associated with. From this perspective, French and Italian draw very similar functional boundaries in the environment of other-repetition, with distinct contours associated with seeking confirmation, seeking completion, challenging, and registering (Persson, this issue; Rossi, this issue). So, above and beyond the surface form of individual intonation contours, we must look at the internal organisation of the repertoire.

This discussion shows that the articulation of categories for comparison in pragmatic typology requires us to combine formal, structural, and functional criteria. In the domain of grammar, such combination allows us to compare parts of speech by reference to cross-linguistic propositional acts such as reference, predication, and modification. In the domain of particles, we can juxtapose items that share a structural position in a turn (e.g. initial) and common functional properties (e.g. 
signalling the speaker's 'change of state'). In the domain of prosody, we have seen that the comparison of intonation contours must be done by reference to the oppositional relations between them in their respective repertoires. That said, other prosodic features may be more amenable to direct comparison: as we see in the following section, these are features that are not strictly bound up in language-specific phonologies, and are therefore more free to vary according to language-independent principles (see Szczepek Reed \& Persson 2016).

In sum, pragmatic typology is concerned with similarities and differences in situated language use and communicative behaviour across human groups. Starting from a common conversational structure, its aim is to uncover both invariants of conduct grounded in the generic organisation of interaction and distinct patterns driven by the particulars of different linguistic and cultural systems.

\section{P R O S O D Y}

As the title of this article suggests, a key contribution of the present project is the bringing of prosody into pragmatic typology, using other-repetition as the terrain for this new development. Prosody is an established domain of linguistic analysis. However, its conceptualisation and boundaries can vary significantly between different traditions of research. So, just as with other-repetition, some specification of the domain, and of our approach to it, is in order.

Prosody can be generally understood as the nonlexical acoustic-auditory features of speech. This means sound patterns that do not concern the structure and meaning of words, but that belong to the organisation of a whole utterance, including its phrasing, information structure, pragmatic function, and other interactional properties.

Within prosody, the most well known subdomain of analysis is intonation. The simplest definition of intonation is as speech melody: the 'ensemble of pitch variations in the course of an utterance' ('t Hart, Collier, \& Cohen 1990:10). ${ }^{3}$ Intonation has its own tradition of study, which has often involved a separation between aspects of the speech sound that are considered 'linguistic' and others that are considered 'paralinguistic', that is, not part of linguistic structure and meaning (Crystal 1969; Ladd 2008). This much debated distinction is, however, unnecessary when the speech sound is analysed in its full extent and relevance for social interaction (Local \& Walker 2005). What is more useful to distinguish is between different ways in which the sound-meaning relation can be structured. One way is discrete, where changes in sound can be partitioned into contrastive units or categories (e.g. a rising vs. a rising-falling contour) and changes in meaning corresponding to these categories are mainly arbitrary-conventional. The other way is gradient, where changes in sound along a continuous variable (e.g. the height and depth of a rising-falling contour) correspond to gradual, analogic changes in meaning (e.g. the degree of the speaker's displayed surprise). These two kinds of sound-meaning relation, or modes of signification, often 
co-occur and interact in the speech signal, and both of them have been shown to give rise to orderly structures that have communicative and social import. This perspective encourages the treatment of intonation as one of several potentially relevant dimensions of the speech sound, with no a priori privileged status over other parameters (Kelly \& Local 1989; Walker 2013). So intonation—or perhaps more simply, pitch contour - is here considered on a par with parameters including pitch onset, that is, the level of pitch at the beginning of the utterance (higher or lower), and pitch span, the excursion of pitch in the course of the utterance (narrower or wider), as well as with nonpitch parameters like volume (louder or softer) and speech rate (faster or slower). This approach allows us to consider the same speech sound from different angles, either focussing on a particular prosodic feature, or identifying stable bundles of features that work together, on the condition that the categories of analysis be warranted on the basis of what is relevant to participants in producing and understanding talk. This is part of a more general approach that combines linguistics with conversation analysis (see CouperKuhlen \& Selting 2018). While putting interaction at the centre stage of linguistic distinctions, this approach continues to draw on the knowledge accumulated in other areas of linguistics, provided that the previously identified structures and mechanisms can stand the test of what is observable in interaction. In this respect, it is worth saying a few more words about intonation to further situate our approach relative to the extensive literature on the topic.

Intonation has been often examined by looking primarily at terminal pitch (e.g. rising or falling), under the explicit or implicit assumption that this contributes to the meaning of an utterance. In fact, intonation comprises more than the end of an utterance and crucially involves the pattern created by prominent movements of pitch around one or more of the utterance's stressed syllables. These prominent movements are commonly referred to as pitch accents, but can also be more plainly seen as 'landmarks' (Nolan 2006:436). While agreeing on the existence of these landmarks, different traditions in intonational phonology diverge in how they analyse intonational structure and how they connect it to function and meaning. For instance, in the socalled British tradition (e.g. O'Connor \& Arnold 1973), form-meaning mappings are established HOLISTICALLY by associating the global shape of the melody - the contour or tune (e.g. low rise, rise-fall) - to attitudes such as 'tentative', 'deprecatory', 'impressed', 'pleading'. By contrast, in the autosegmental-metrical tradition (Pierrehumbert 1980; Beckman \& Pierrehumbert 1986), form and meaning are approached COMPositionalLy. The melody is decomposed into a string of localised tonal events, the atoms of which are $\mathrm{H}$ (igh) and $\mathrm{L}$ (ow) pitch targets as well as combinations of them into rising $(\mathrm{L}+\mathrm{H})$ or falling $(\mathrm{H}+\mathrm{L})$ pitch accents. These events, comprising pitch accents and edge tones, constitute distinct types of tonal 'morphemes', each of which makes an independent contribution to the total meaning of the melody (Pierrehumbert \& Hirschberg 1990).

In our project, the formal analysis of intonation follows a somewhat hybrid approach that includes aspects from both the British and the autosegmental-metrical 
traditions. Our descriptions of speech melody emphasise the coherence of its global shape. At the same time, the labels we use to distinguish between alternative melodies typically focus on the section from the primary (or nuclear) pitch accent to the end of the utterance (e.g. rise from low, rise-fall-rise). We also pay special attention to the alignment of pitch components with relevant syllables, making reference to targets or levels of pitch (e.g. H[igh], L[ow]), and in some cases offer transcriptions following ToBI conventions (Silverman, Beckman, Pitrelli, Ostendorf, Wightman, Price, Pierrehumbert, \& Hirschberg 1992).

As far as the study of meaning is concerned, however, our project differs substantially from both traditions, as well as from most other frameworks. The reason is that most research on intonational meaning has been largely based either on introspection or on laboratory speech, or on speech elicited in constrained experimental settings. Such speech often sounds and works differently from conversational speech, and the contexts of use and functions of intonation in the laboratory are significantly impoverished compared to naturally occurring conversation. A few studies in the field of intonational phonology are based on more spontaneous speech produced in task-oriented dialogues (Carletta, Isard, Doherty-Sneddon, Isard, Kowtko, \& Anderson 1997; e.g. Grice \& Savino 2003; Savino \& Grice 2011). This approach adds a significant degree of ecological validity to the analysis, which is framed in terms of 'conversational moves', including initiating and responding moves, and types of moves such as 'queries', 'checks', 'objections', and 'acknowledgements'. At the same time, the identification of these moves is based primarily on information status (given, new, accessible) and on the speaker's degree of confidence about it. This information-centred approach limits the reach of these studies into the range of meanings and functions that intonation serves in conversation. ${ }^{4}$ In the present project, we analyse conversation as social action. Action distinctions are induced from sequential development and from the responsive behaviour of participants, and the attribution of meaning is grounded in details of talk and other conduct that exhibit the participants' own understanding of each other's actions. The phenomenon of other-repetition offers an environment featuring a diverse range of social actions, allowing us to connect intonational and prosodic form to meanings that go beyond the speaker's degree of confidence, spanning issues of mutual understanding, alignment, agreement, and affiliation.

The breadth of social-interactional contingencies surrounding other-repetition along with the analytical precision afforded by a sequential, action-based approach to conversation gives us an advantage also over other lines of explanation of prosodic meaning based on the proposal of 'biological codes' (Ohala 1983; Gussenhoven 2016). These codes include an iconic relation between prosodic meaning and the anatomical-physiological processes affecting vocal fold vibration: low pitch generally means 'confidence' because it is prototypically associated with the larynx of a large, dominant creature, whereas high pitch generally means 'uncertainty' by association with the larynx of a small, submissive creature. 
These associations, however, are rather abstract and hard to apply to languagespecific systems.

Having situated the present project in relation to the study of prosodic form and function generally, we can now consider this domain more specifically with respect to cross-linguistic comparison. To pick up where we left off in the previous section, we have said that the analysis of intonation contours across languages requires the mediation of comparative concepts to formulate commensurable form-function distinctions. In what follows, we can expand the discussion to other prosodic features that are instead more amenable to direct comparison.

Among these features are the volume or loudness of an utterance and the 'scaling' of its pitch variations, including the height of its onset and the size of its span, as well as more complex features like register, which refers to the relative height of the whole pitch configuration. Crucially, such features can be measured on the basis of two different reference points. One is the speaker's own voice range, which gives us a measurement in terms of INDIVIDUAL parameters; the other is previous talk by the same or another speaker, in which case the parameters are RELATIONAL. Pitch and loudness relations with previous talk have been shown to be central to a wide range of interactional tasks in several languages, and to participate in the constitution of composite prosodic practices referred to as 'upgrading' and 'downgrading' (Curl 2005; Ogden 2006). The former practice typically includes higher pitch onset or register, wider span, and louder volume, whereas the latter typically includes lower pitch onset or register, narrower span, and softer volume. This contrast between prosodic 'upgrading' and 'downgrading' has a counterpart in terms of individual parameters that can be referred to as 'large' and 'small' prosody (Pillet-Shore 2012). The use of these composite prosodic practices and more generally of the pitch and loudness features discussed above, along with features of tempo and articulation, is not strictly constrained by lexical and intonational phonology and is therefore more amenable to direct comparison across languages. For this to work, however, the use of these features has to be situated in conversational structure, including turns at talk and turn-constructional units (Sacks, Schegloff, \& Jefferson 1974). These are the units that 'enable us to establish structural "sameness", and to compare "like with like" both phonetically and interactionally' (Local 2007:1). Moreover, the conversational phenomenon of other-repetition has a further advantage for prosodic analysis, in that the varying lexical content of a repetition is, in a way, a constant across languages, and therefore provides an especially good locus for examining prosodic variation, as well as its combination with other linguistic and nonlinguistic resources.

Now that we have introduced the conversational phenomenon under analysis, situated its study in the field of pragmatic typology, and specified our approach to the analysis of prosody, we can recap the central questions of the project: what is the role of prosody in distinguishing the functions of other-repetition? How does prosody interact with other interactional resources? And how does this process differ across languages? 


\section{A T A A N M E T H O D}

The project reported on in this special issue is based on data from naturally occurring conversation in five languages, collected and analysed by a team of researchers (see Table 1) that worked together between 2015 and 2018, with a primary base at the University of Helsinki. ${ }^{5}$

TABLE 1. Languages and researchers.

\begin{tabular}{llll}
\hline \hline Language & Family & Location & Researcher(s) \\
\hline English & Indo-European/Germanic & UK, US & Elizabeth Couper-Kuhlen \\
Finnish & Finno-Ugric & Finland & Melisa Stevanovic, Auli Hakulinen, Anna Vatanen \\
French & Indo-European/Romance & France & Rasmus Persson \\
Italian & Indo-European/Romance & Italy & Giovanni Rossi \\
Swedish & Indo-European/Germanic & Finland & Martina Huhtamäki, Jan Lindström, Anne-Marie \\
& & & Londen \\
\hline \hline
\end{tabular}

Detailed information on the languages, the particular variety or varieties examined, and on the corpora used is given in the language-specific articles. However, a few general notes on our corpora are in order here. All corpora include recordings of face-to-face conversation, with the English, Finnish, and French corpora also featuring telephone conversations. A large proportion of the conversations is informal, taking place in domestic settings among family, friends, and neighbours. Some French and Swedish recordings are from institutional settings, including service encounters at a ticket office, in a bakery, in a cheese shop, as well as workplace interactions and radio phone-in shows. Pooling data from these different settings is warranted by the fact that we did not observe any particular effects of setting on the resources that speakers use to design and understand other-repetitions. What we do observe is that certain kinds of institutional interactions, especially service encounters and radio phone-in shows, can increase the frequency of certain functions of other-repetition, especially registering (see extract (1) below). These imbalances in the frequency of certain functions, however, do not affect the main goal of the project, which is to account for how speakers and recipients distinguish among them.

All of the studies in this special issue draw on methods from linguistics and conversation analysis, including two particular intersections between these fields: the prosody and phonetics of talk-in-interaction, and pragmatic typology. ${ }^{6}$ The main tenets and specifics of the methods used in these fields have already been extensively discussed in the previous two sections. With respect to pragmatic typology, however, it may be worth going over some of the practical steps of its mixed methodology to better situate the work reported in this special issue within the larger project of which it is part. As already discussed, the project as a whole joins a recent lineage of research involving the structured comparison of a formally and 
sequentially delimited phenomenon across languages. This begins with data sessions devoted to the qualitative analysis of audiovisual recordings in each language, with a thoroughgoing examination of each exchange in its own right, situated in the richness of its social context and enmeshed in a flux of other events. This allows analysts to get a firm grasp of the details of single cases before making generalisations across cases, and to identify deviations from a pattern that may reveal the violation of an underlying norm, thereby providing evidence for it. This qualitative analysis is also aimed at developing a principled definition of the phenomenon, which requires the discussion of borderline cases. Firming up the boundaries of the phenomenon is a prerequisite for the systematic collection of cases on a large scale; together with the qualitative analysis of linguistic and interactional patterns, this provides the foundation for the subsequent quantitative analysis. This phase begins with the design of a coding scheme to capture the core set of formal and functional categories, parameters, and variables that have emerged from the qualitative analysis and that are amenable to quantification. The coding scheme is piloted, revised, and then further refined after group coding exercises, which serve to increase the calibration among coders. When the coding scheme has been sufficiently tested and assimilated, the independent coding of each language's dataset can begin. The last step in the process is a test of intercoder reliability.

The coding scheme designed for the quantitative stage of the present project and the main quantitative cross-linguistic analysis are in preparation for publication at a later stage. The findings reported in the language-specific articles in this special issue are primarily the product of qualitative analysis.

\section{DELIMITING THE PHENOMENON}

We have already delimited our phenomenon as: verbal repetition, intended as exact or modified replication of lexical material, produced by someone other than the speaker of the first saying, so as to problematise or otherwise engage with what has been said making a response conditionally or optionally relevant. Here we draw the boundaries of the phenomenon in greater detail.

Let us begin by describing its basic sequential structure. Extract (1) reproduces the final moments of a service encounter at a ticket office (from Huhtamäki, Lindström, \& Londen, this issue). Before the extract begins, the customer has sought and obtained information about an upcoming event from the ticket seller, and has begun moving away from the counter. The customer then stops and turns back to the ticket seller to double check on the time of the event (line 1).

(1) Swedish (HEL_LUC_RL_004_2 00:05)

$\begin{array}{lll}1 & \text { Customer: å de va } & \text { (.) klockan } \\ \text { 'and it was } & \text { (.) at' } \\ 2 & (0.3) & \end{array}$




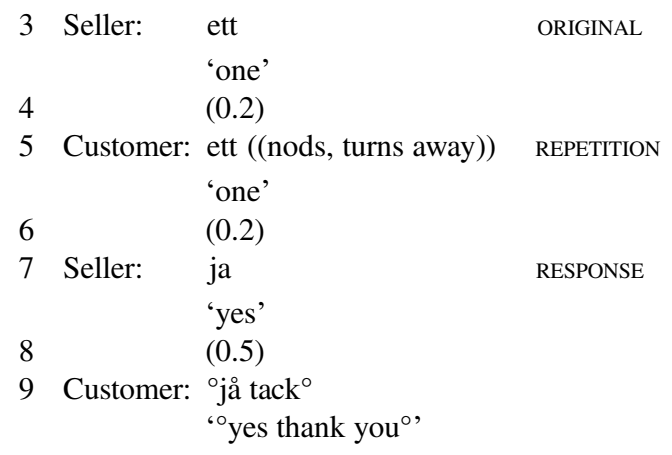

This example makes very clear the three-part structure of an other-repetition sequence: in the original turn, Speaker A says something; in the repetition turn, Speaker B repeats all or part of what Speaker A has said; in the response turn, Speaker A responds to the repetition. ${ }^{7}$ This pattern is in many respects analogous to that of an other-initiated repair sequence (Schegloff, Jefferson, \& Sacks 1977; Dingemanse \& Enfield 2015). However, the phenomenon of other-repetition is formally narrower and functionally wider than other-initiated repair, so it is important to further specify its boundaries in terms of linguistic construction, turn structure, sequential position, and response relevance.

\section{Linguistic construction}

Repetition is here intended as a lexical 'near copy' of the original saying (word, phrase, clause) with no or little modification. Modification is limited to deictic shifts between first and second person (e.g. extract (5)), changes in word order (e.g. extract (5)), the insertion of a particle, adjective, or adverbial (e.g. A: he wants a hug B: now he wants a hug?), and pronominalisation (e.g. A: Mary sold her car B: she sold her car?). We exclude repetition in the form of a pro-verb that stands for a verb in the original saying (e.g. A: they really love him $\mathrm{B}$ : do they?/they do?).

\section{Turn structure}

The repetition is the first unit in the turn or is preceded only by a turn-initial particle (e.g. oh). We exclude repetitions framed by a preface like the English what do you mean $x$, Italian come $x$, and French comment ça $x$, as well as repetitions with an in situ question word (e.g. she saw who?). We do include repetitions followed by further turn-constructional units.

\section{Sequential position}

The repetition is produced in next turn to the original saying or soon thereafter. While there can be intervening talk, this is generally restricted to cases of overlap 
and concurrent sequences, for example when the repetition speaker needs to finish off another line of talk before addressing the original turn. We exclude cases in which the repetition is produced after an earlier response to the original turn (e.g. A: I hate him B: why?! (0.3) you hate him?!).

\section{Response relevance}

As already discussed above, our focus in this project is on other-repetitions that make a response conditionally or optionally relevant by the original speaker. Optional response relevance applies especially to repetitions enacting a third-position action, typically registering (see extract (1)). Although they do not mandate a response, these repetitions create an opportunity for it, and recipients regularly volunteer it; this 'displays an inclination to treat the repeat as RESPONSE-WORTHY' (Schegloff 1997:527). With repetitions enacting a third-position action, responses are normally limited to confirmation. With initiating actions, the range extends beyond confirmation to include completion, clarification, justification, and backing down, among others. Laughter may be infused in these types of responses to add a particular emotive colouring.

Because the response relevance set up by an other-repetition plays an important role in delimiting the phenomenon in focus here, I now illustrate the most recurrent types of response with examples.

Confirmation is the most frequent type of response. We have already encountered an example in extract (1), where confirmation is accomplished by a positive polar interjection ('yes'). Our definition of confirmation is functional and encompasses various practices ranging from polar interjections to (responding) repetitions to gestures such as head nodding. It also subsumes finer-grained distinctions within the domain, for example, between 'confirming' and 'affirming' (Sorjonen 2001), though we do keep track of these when relevant for the analysis (see extract (5)). The opposite of confirmation is of course disconfirmation, which is likewise defined functionally, encompassing polar interjections, head shaking, etc.

Completion refers to the reiteration of a segment of the original saying to fill a gap left by a partial repetition (Koshik 2002; Rossi 2015; Persson 2017). This is typically a 'missing bit' that was not heard or understood, as illustrated in the following extract (from Persson, this issue).

(2) French (FTELPV19_0:05)

1 E: oui bonjou:r j’organise une r- (.) conférence samedi: et j'aurais aimé 'yes hello I'm organising a r- conference on Saturday and I'd like'

2 savoir si vous livriez des collations pour les pauses 'to know if you might deliver refreshments for the breaks'

$3 \quad($.

4 C: $\quad$.hh (.) pour le:s

'.hh for the:' 


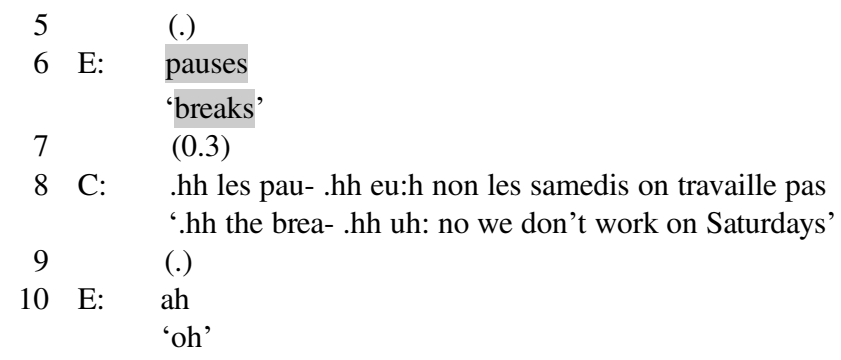

Clarification is intended as the explanation or specification of factual information or reference, aimed at making it more intelligible or plain. Extract (3) below gives us an example of clarification of a reference to an object. At line 1, Veke is talking about sacks of garden grit, referring to them as papusäkkejä 'bean sacks'. After his interlocutor Sami repeats the problematic reference papu 'bean' (line 6), Veke clarifies it with Leca-sora, that is, 'grit' (sora) produced by the gardening brand 'Leca'.

(3) Finnish (SG 096 B08_03.39)

1 Veke: .hhh mä taas kannoin noita papusäkkejä

I again carry-PST those bean-sack-PL-PAR

'.hhh I carried the bean sacks again'

2 tonne kellarii tualt pihalta ne oj jo

'to the cellar from the garden they have already'

3 jäätyny tonne maaha osittai kiinni ja,

'partly frozen into the ground and'

$4 \quad$ ((yawns))

$5 \quad$.hhh hhhho[h

6 Sami: $\quad[\mathrm{pa}[\mathrm{pu}$,

'bean'

7 Veke: $\quad$ ni-

8 niitä hhh Leca-sora,

'that hhh Leca-grit'

9 Sami: Leca-[sora,

'Leca-grit'

10 Veke: [säkkejä, mitä tos

'sacks that are'

11 [pihal siälä sun täälä viälä,

'still around in the garden'

12 Sami: [aha jaa-jaa,

'aha yeah yeah'

By justification we intend the action of defending or legitimising a behaviour, opinion, or expression. In the following extract (from Couper-Kuhlen, this 
issue), Bob is telling two friends about the amateur play he will soon be starring in at school. As evidence of the popularity of the play, Bob notes that even Megan, a mutual acquaintance from Singapore, has heard of it (lines 9-13). At this point, his friend Jack repeats what Bob has just said ('even she'd heard of it') to question its acceptability (line 14), conveying that it can be heard as demeaning or disrespectful of Megan. In response, Bob produces a justification (line 15) and subsequently continues to defend himself after Chip follows up on the challenge.

(4) English (Swimmers_01.23)

1 Bob: yeah $\underline{\text { YOU }}$ heard [of it didn't you?

2 Jack: [I've hEard of it yeah,

3 Bob: [yeah_

4 Jack: [well I've- well I've sEen it in my SCHOOL;

$5 \quad(0.7)$

$6 \quad<<\mathrm{p}>$ oh $\operatorname{rg}[\mathrm{ht} .>$

7 Jack: $\quad\left[\mathrm{sO}\right.$ : $_{-}$

$8 \quad(0.9)$

9 Bob: and you know uhm:: you know MEgan.

$10 \quad(0.4)$

11 Jack: YEAH;

$12 \quad(0.5)$

13 Bob: $\uparrow$ even SHE'D heard of it $\uparrow$;

14 Jack: heh heh .hh Even $\uparrow$ 'SHE:'D heard'v it (hh),

15 Bob: well nO I mean she's from $\uparrow$ SINGapo(hh)re;

$16 \quad(0.7)$

17 Chip: pfff [A:ND? ((laughs))

18 Jack: [((laughs))

19 Chip: pretty sure they've you know,

$20 \quad(0.4)$

21 Bob: $\uparrow$ no no like- $\uparrow$

22 Chip: they have [CUL]ture there.

23 Bob: [just-]

$24 \quad(0.3)$

25 Bob: I'm not being u::hm I'm not being FUNny.

Whilst justification is aimed at holding one's ground, another way of responding to a challenge is by backing down, that is, by modifying the stance or expression in question (see Schegloff 2007:151-55). Backdowns can range from a complete retraction to the gradual qualification of the previously held stance or expression, to a mitigated, weaker, or emended version.

Responses to other-repetition can of course contain more than one type of action, for example, confirmation followed by clarification or justification. Some combinations, however, such as justification and backing down, are unlikely. Also, completion is a very specific operation that tends to occur alone. 
One of the basic findings of the present project is that other-repetition is used to accomplish certain recurrent types of action that are common across languages. These types of action can be seen as generic functions that emerge out of the complex social-interactional contingencies and nuances that other-repetitions are enmeshed in - regular patterns that cut across the thick particulars of each case. Most types of action that we identify here have already been described, more or less extensively, in earlier research, including in studies of other-repetition. Some types have also already been found to be cross-linguistically recurrent in an earlier comparative project on other-initiated repair (Dingemanse \& Enfield 2015). In the present project, we build on this previous research to map out a larger space of action types ranging from actions that fall within repair initiation to actions that extend beyond repair initiation, to actions that are alternative to it. Our systematisation of this action space and of the distinctions within it goes hand in hand with our goal of explaining how people design and recognise the actions accomplished by other-repetition, and how this process is affected by crosslinguistic variation. Some of the action types discussed below are strongly associated with particular types of responses discussed in the previous section, including by relations of conditional relevance and type conformity (Schegloff \& Sacks 1973; Raymond 2003); for other action types, the response space is wider and less constrained.

\section{Initiating repair}

Actions of initiating repair suspend the progress of conversation to deal with a 'barrier' that needs to be removed in order for intersubjectivity to be maintained and for progress to resume (Hayashi, Raymond, \& Sidnell 2013:13). Repetition can be deployed in different phases of the repair process, but here we are specifically interested in the initiation of repair by a person other than the speaker of the trouble-source. In this role, repetition is a practice for 'restricted' repair initiation (Dingemanse \& Enfield 2015) that narrows the problem down, instead of leaving it 'open' (Drew 1997). This is because repetition displays greater access to the preceding talk - compared, for instance, to interjections (e.g. huh?) and question words (e.g. what? who?) - and is therefore stronger in locating and identifying where and what the trouble is (Schegloff et al. 1977:369; Sidnell 2010:117-18, among others). Within actions of initiating repair, we can distinguish different types accomplished by other-repetition. These types are best defined by reference to the kind of repair solution they seek. Here is where the pairing of initiating and responding action is characterised by conditional relevance and type conformity.

Seeking completion is a type of action that is associated with 'hanging' or 'incomplete' repetitions (Rossi 2015; Persson 2017), where the speaker replicates the preceding talk up to and excluding the problematic part in order to 'frame' it 
(Jefferson 1972). This prompts the previous speaker to fill in the rest, an example of which we have already encountered in extract (2).

Seeking confirmation is a type of action that has been studied as part of the broader phenomenon of 'understanding checks' (Schegloff et al. 1977) or 'candidate understandings' (Heritage 1984:319), where the speaker presents a hypothesis as to what has been said or meant by the previous speaker. Here, we are interested in seeking confirmation only when done by repeating what has been said. An example can be found in the following extract (from Stevanovic et al., this issue). Anu and Susa have been talking about Susa's application to a vocational school. When the extract begins, Anu is asking Susa what her plans are in case she is not admitted (lines 1-2). Anu's question is produced very softly, almost in a whisper. Susa then repeats part of it to check that she has correctly understood the scenario invoked by Anu, that is, whether she is asking about the eventuality of Susa being not admitted to the school, as opposed to being admitted.

(5) Finnish (SG 151_21:45)

1 Anu: mitä sie muute Susa meinaat tehä jos et what $2 \mathrm{SG}$ by-the-way NAME intend-2SG do-INF if NEG-2SG

2 sie pääse kouluu. 'by the way Susa what do you intend to do if you'

2SG be.admitted school-ILL

'don't get into the school'

3 Susa: jos [mie] $\underline{\mathrm{em}}$ pää[se] kouluun.

if $1 \mathrm{SG}$ NEG-1SG be.admitted school-ILL

'if I don't get into the school'

4 Anu: $\quad\left[\left(^{\circ}-^{\circ}\right)\right] \quad\left[{ }^{\circ}\right.$ nii $\left.^{\circ}\right](($ nods $))$

${ }^{\circ} \mathrm{nii}^{\circ}(\approx \mathrm{yes})$

5 Susa: em mie oo itseasias ajatellu

'I haven't actually thought ((about it))'

6 mie aattele et pitää keksii sit.

'I thought that one has to find out when the time comes'

Anu's confirming response to Susa's repetition comes in the form of a positive polar interjection accompanied by a nod. Note that speakers of Finnish can select between two main verbal alternatives for confirming: nii $(n)$ and joo, both translatable as 'yes'. The fact that Anu uses nii here is evidence that she understands Susa's repetition as seeking confirmation (Sorjonen 1996).

Seeking clarification is a type of action by which the repetition speaker raises a problem of comprehension such as not recognising a reference or not being able to contextualise what has been said, which necessitates further specification or explanation (see e.g. Wu 2006:76). We have already encountered an example of seeking clarification in extract (3). There the repetition does not 'offer' a candidate hearing or understanding to be confirmed or disconfirmed, but 'requests' a more complex repair operation with supplementary content to be provided by the previous 
speaker (Schegloff 2004; Dingemanse \& Enfield 2015). While confirmation is still a possible response to a repetition seeking clarification, it is typically not treated as sufficient (see Persson, this issue).

\section{Beyond initiating repair}

In this section, we discuss actions that go beyond initiating repair simpliciter (Lerner, Bolden, Hepburn, \& Mandelbaum 2012:199), meaning that their import involves more than dealing with a problem of hearing or understanding. This 'more' often has to do with the unexpectedness of what the previous speaker has said (Selting 1996; Wilkinson \& Kitzinger 2006), for example, because it reports an extraordinary or remarkable fact, or because it presents an inappropriate or questionable view. In some cases, the work of dealing with unexpectedness is done IN ADDITION TO initiating repair; in others, it is done INSTEAD OF initiating repair, depending on whether or not there is a concurrent, genuine indication of a lack of understanding (Schegloff 1997:505; Kendrick 2015:181-82). This distinction, however, is not always clear, not only for analysts but also, arguably, for participants. For this reason, and for the purposes of systematisation and comparison of our project, we refer to these actions as going BEYOND initiating repair, to capture their potential to either subsume or transcend initiating repair.

Actions that go beyond initiating repair to deal with unexpectedness are less aptly defined by the kind of response they make relevant, in that the range of response options is wider and less constrained. Rather, they are better defined in terms of the interactional stance or position they express (see also Wu 2006:78). Among the many nuances and colourings that actions in this domain can take, there are two recurrent types that stand out.

One is displaying surprise (Selting 1996; Wilkinson \& Kitzinger 2006). This action has been extensively studied especially with reference to expressions of 'ritualised disbelief' (Heritage 1984:339) such as really, seriously, and you're kidding, which formally question the veracity of what has been said as a way of conveying the speaker's astonishment. Repetition is another practice for accomplishing this. Just like really and similar expressions, repetitions displaying surprise can be responded to with confirmation. These confirmations, however, often look different from those produced in response to a candidate hearing or understanding (cf. extract (5)) and do not usually conclude the sequence, which tends instead to be expanded with further expression of surprise, elaboration on the topic, and affiliation. In the following extract (from Persson, this issue), Adèle is talking about the procedures for keeping foodstuffs at the McDonald's she works in, which include the freezing of nuggets, filets, and 'cakes too' (line 5). In response to Béa's display of surprise at the revelation that 'cakes too' are frozen, Adèle confirms with ouais ouais 'yeah yeah' (line 8). The reduplicated 'yeah' conveys assurance of the reported fact and indicates the relevance of a stronger form of confirmation here. Béa then continues her display of surprise with a 
loud, open-mouthed outbreath (line 10), which is followed by Adèle's elaboration on the topic.

(6) French (Mac-cle-sd_20:30)

1 Adèle: parce qu'en fait tout est surgelé tu vois les nugge:ts les file:ts .hhhh ' 'cause actually it's all frozen y'know the nuggets: the filets: .hhhh'

2 Béa: a:h [d'accord] 'oh: okay'

3 Adèle: [eu:hm ]

$4 \quad(0.4)$

5 Adèle: et les gâteaux aussi ils sont surgelés= 'and the cakes too they're frozen='

6 Béa: =les gâteaux aussi '=the cakes too'

$7 \quad$ (.)

8 Adèle: ouais ouais 'yeah yeah'

$9 \quad(0.3)$

10 Béa: hh ((short, relatively loud outbreath with audibly open mouth))

11 Adèle: e:t- tout- en fait tout est surgelé- tout ce qui est frai:s 'and:- it's- actually it's all frozen- everything that's fresh:/chilled'

12 eu:h tu sais immédiatement c'est tout c'qui est sala:des euh lait

13 Béa: ouais

yeah

Another type of action in the domain of unexpectedness is questioning the acceptability of the preceding talk or, in other words, challenging. This has been the topic of a large body of research on the relation between repair initiation and incipient or manifest disagreement (Schegloff 2007:151-55), part of which has focussed on other-repetition (Jefferson 1972; Wu 2006; Svennevig 2008; Robinson \& Kevoe-Feldman 2010; Benjamin \& Walker 2013, among others). Issues of acceptability typically concern the truthfulness, accuracy, or appropriateness of what has been said. The difference from surprise is that here unexpectedness is morally and negatively charged. By questioning acceptability, the speaker claims that something is 'wrong' with the preceding talk, making the action negatively valenced. We have encountered an example of this in extract (4). In this and other cases, the speaker's stance might also be concurrently characterised as 'surprised', but crucially an issue of acceptability takes the stance further and gives the action a distinct import, changing the space of response options and the relations between them. ${ }^{8}$ In extract (4), the previous speaker defends himself; in other cases, he may back down on what he has said. Yet another alternative is for the previous speaker to simply confirm—when this happens, however, confirmation amounts 
to resisting the challenge and often leads to more explicit disalignment and disaffiliation between participants (Jefferson 1972:310-12).

\section{Other than initiating repair}

In this section, we discuss actions that are more clearly alternative to initiating repair, where repetition is deployed to a rather different effect and an analysis of it as involving the initiation of repair 'would be incorrect' (Schegloff 1997:505). Perhaps the most recurrent and well established type of action in this domain is registering (Sorjonen 1996; Schegloff 1997; Persson 2015, among others). The action of registering is alternative to initiating repair in that, instead of signalling a trouble of hearing or understanding, the speaker acknowledges receipt of the preceding talk, which is 'taken in' rather than problematised. In a case like extract (1), this is visible in the fact that the speaker turns away while producing the repetition (line 5). At the same time, an action of registering often occasions a confirmation by the previous speaker. The social relevance of this is particularly clear in certain institutional settings where there are reasons for ratifying the correct transfer of information as part of a transaction or instruction, for example, concerning a type of service, the quantity of some good, or the time of an event (Goldberg 1975). A registering repetition serves to put the information 'on record' (Lee 2016). The fact that confirmation, when given, is 'volunteered' rather than mandated is reflected in the design of confirmation tokens (Sorjonen 1996; Persson 2015).

The action of registering can also be coloured with additional socialinteractional meanings that go beyond acknowledging receipt of information and involve, for example, displaying appreciation or affiliation (see Stevanovic et al., this issue). Other noninformational functions connect registering with other types of action that are alternative to initiating repair, including 'mulling over' a question (Kelly \& Local 1989:272ff) and 'temporising' before giving a response (Bolden 2009:136-38; see also Couper-Kuhlen 1996:388-90). Further types of action that are alternative to initiating repair are documented elsewhere in this special issue (e.g. Persson, this issue).

To sum up this whole section, the types of action we have described reflect common social-interactional preoccupations that speakers of different languages have in conversation, surrounding mutual understanding, alignment, agreement, and affiliation. The finding that other-repetition is recurrently used to accomplish analogous actions across languages contributes to the body of evidence for a universal infrastructure of human interaction. At the same time, these commonalities in terms of sequential action provide us with yardsticks for comparing how actions are designed in different communities, and how the local resources of specific languages may introduce inflections and nuances of meaning. 


\section{O N C L U S I O N}

The project reported on in this special issue contributes to the development of pragmatic typology as a growing field of research into the universal and culture-specific aspects of language usage and social interaction. The project focusses on a recurrent conversational phenomenon in which a speaker repeats all or part of what another speaker has just said, typically in the next turn. Other-repetition can accomplish very different interactional work, ranging from seeking clarification to expressing surprise to questioning the acceptability of what is said, spanning many of the fundamental preoccupations of human interaction: mutual understanding, alignment, agreement, and affiliation. The puzzle is: how do speakers of different languages distinguish these actions? And how do recipients know what to respond with? In addressing these questions, the project puts at centre stage the resources of prosody, generally understood as the nonlexical acoustic-auditory features of speech, along with other elements of language and context. In so doing, the project breaks new ground by bringing the systematic study of prosody into the field of pragmatic typology.

The payoffs of an approach that situates linguistic analysis and comparison in the realm of natural conversation are many. One is that it allows us to provide new, more grounded answers to questions that have been previously addressed without the support of ecologically valid data. To give an example, previous work in prosodic typology asserts that 'echo questions' (another term for certain otherrepetitions) are 'invariably rising in English, Swedish, French, Portuguese, Romanian and Finnish' (Hirst \& Di Cristo 1998:27). Our analysis demonstrates that this is not the case, that other-repetitions are produced with a variety of intonation contours, and that the use of intonation must be studied together with other aspects of prosody. But the empirical strength of our approach goes beyond prosodic form-function mappings. Focussing on a robust conversational structure (original turn $>$ repetition $>$ response) gives us a controlled environment for studying the interface of prosody with a number of other interactional resources, and therefore to excavate the meanings of prosody from the complexity and richness of conversation. In this project, we adopt a framework 'that is both interactionally sensitive and adequate for systematic comparative analyses' (Enfield, Stivers, \& Levinson 2010:2618), allowing us to uncover basic features of human communication and sociality, in both their universal and language-specific aspects.

\section{N O T E S}

*I wish to thank all the founding members of the project reported on in this special issue for their input and comments on this introduction: Betty Couper-Kuhlen, Auli Hakulinen, Martina Huhtamäki, Jan Lindström, Ami Londen, Rasmus Persson, Melisa Stevanovic, and Anna Vatanen. I am also grateful to Jack Sidnell for his advice and patience through the gestation of the special issue. In the early stages of the project, we benefitted from conversations with Emma Betz, who generously shared literature on other-repetition, and with Mietta Lennes, Richard Ogden, and Francisco Torreira, who participated in 


\section{GIOVANNI ROSSI}

project workshops at the University of Helsinki. The project was hosted and funded by the Finnish Centre of Excellence in Research on Intersubjectivity in Interaction (Academy of Finland grant \# 284595). We owe a particular debt of gratitude to the director of the centre, Marja-Leena Sorjonen, for making this project possible and for her continued support and encouragement.

${ }^{1}$ This and other examples given in parentheses here are simplified versions of actual cases from conversational data.

${ }^{2}$ Free word order can notably increase the possibilities of recasting the same lexical material in different linear arrangements (see Hale 1983); however, it arguably does not alter the fundamental operation of replication that is at the core of repetition.

${ }^{3}$ The patterning of these pitch variations is closely tied to patterns of duration and loudness, and sometimes voice quality.

${ }^{4}$ To be clear, a speaker's degree of confidence or certainty seems to be an important aspect of the meaning conveyed by differently intoned questions in a number of languages (see also Ward \& Hirschberg 1985; Bolinger 1989; Armstrong \& Prieto 2015, among many others) and is conceptually compatible with what conversation analysts refer to as 'epistemic stance'. The issue is not the validity of speaker confidence as a dimension of analysis but the need to situate it in the larger organisation of social interaction.

${ }^{5}$ The researchers listed in the table are the founding members of the project and contributors to this special issue. Later phases of the project involved two more analysts-Minea Tikkanen and Francisco Torreira - and four assistants - Chris Carling, Jonna Malaska, Emma Sepänaho, and Maiju Viitanen. We are grateful to these other project members for indirectly contributing to the research reported here.

${ }^{6}$ Extracts in this special issue are transcribed according to conversation-analytic conventions (Hepburn \& Bolden 2013). Focal turns may include interlinear glosses following the Leipzig standards (https://www.eva.mpg.de/lingua/resources/glossing-rules.php). In extracts from English and Italian, traditional conversation-analytic transcription is supplemented with conventions from interactional linguistics (GAT 2) to better represent certain prosodic and intonational features (Couper-Kuhlen \& Barth-Weingarten 2011).

${ }^{7}$ In a minority of cases, the response is produced not by Speaker A, but by Speaker C, a third participant. Also, Speaker B may expand the sequence by acknowledging the response, as it happens in extract (1).

${ }^{8}$ For the purposes of categorisation, this is grounds for conceptualising an issue of acceptability as potentially subsuming surprise, while necessarily going beyond it.

\section{R E F E R E N C E S}

Armstrong, Meghan E., \& Pilar Prieto (2015). The contribution of context and contour to perceived belief in polar questions. Journal of Pragmatics 81:77-92.

Beckman, Mary E., \& Janet B. Pierrehumbert (1986). Intonational structure in Japanese and English. Phonology Yearbook 3:255-309.

Benjamin, Trevor M., \& Traci S. Walker (2013). Managing problems of acceptability through high risefall repetitions. Discourse Processes 50(2):107-38.

Bennett-Kastor, Tina L. (1994). Repetition in language development: From interaction to cohesion. In Barbara Johnstone (ed.), Repetition in discourse: Interdisciplinary perspectives, vol. 1, 155-71. Norwood, NJ: Ablex.

Blum-Kulka, Shoshana; Juliane House; \& Gabriele Kasper (eds.) (1989). Cross-cultural pragmatics: Requests and apologies. Norwood, NJ: Ablex.

Bolden, Galina B. (2009). Beyond answering: Repeat-prefaced responses in conversation. Communication Monographs 76(2):121-43.

Bolinger, Dwight (1957). Interrogative structures of American English. Tuscaloosa: University of Alabama Press.

(1989). Intonation and its uses: Melody in grammar and discourse. Palo Alto, CA: Stanford University Press. 
Brown, Penelope (1998). Conversational structure and language acquisition: The role of repetition in Tzeltal. Journal of Linguistic Anthropology 8(2):197-221.

(1999). Repetition. Journal of Linguistic Anthropology 9(1-2):223-26.

\& Stephen C. Levinson (1987). Politeness: Some universals in language usage. Cambridge: Cambridge University Press.

Carletta, Jean; Stephen Isard; Gwyneth Doherty-Sneddon; Amy Isard; Jacqueline C. Kowtko; \& Anne H. Anderson (1997). The reliability of a dialogue structure coding scheme. Computational Linguistics 23(1):13-31.

Couper-Kuhlen, Elizabeth (1996). The prosody of repetition: On quoting and mimicry. In Elizabeth Couper-Kuhlen \& Margret Selting (eds.), Prosody in conversation: Interactional studies, 366-405. Cambridge: Cambridge University Press.

_ \& Dagmar Barth-Weingarten (2011). A system for transcribing talk-in-interaction: GAT 2. English translation and adaptation of Margret Selting, et al., Gesprächsanalytisches Transkriptionssystem 2. Gesprächsforschung: Online-Zeitschrift zur verbalen Interaktion 12:1-51.

_ \& Margret Selting (2018). Interactional linguistics: Studying language in social interaction. Cambridge: Cambridge University Press.

Croft, William (2003). Typology and universals. 2nd edn. Cambridge: Cambridge University Press.

Crystal, David (1969). Prosodic systems and intonation in English. Cambridge: Cambridge University Press.

Curl, Traci S. (2005). Practices in other-initiated repair resolution: The phonetic differentiation of 'repetitions'. Discourse Processes 39(1):1-43.

Dingemanse, Mark, \& N. J. Enfield (2015). Other-initiated repair across languages: Towards a typology of conversational structures. Open Linguistics 1:96-118.

— \& Simeon Floyd (2014). Conversation across cultures. In N. J. Enfield, Paul Kockelman, \& Jack Sidnell (eds.), The Cambridge handbook of linguistic anthropology, 434-64. Cambridge: Cambridge University Press.

Drew, Paul (1997). 'Open' class repair initiators in response to sequential sources of troubles in conversation. Journal of Pragmatics 28(1):69-101.

Du Bois, John W. (2014). Towards a dialogic syntax. Cognitive Linguistics 25(3):359-410.

Enfield, N. J.; Tanya Stivers; \& Stephen C. Levinson (2010). Question-response sequences in conversation across ten languages: An introduction. Journal of Pragmatics 42(10):2615-19.

Goldberg, Jo Ann (1975). A system for the transfer of instructions in natural settings. Semiotica 14(3):269-95.

Greenberg, Joseph H. (1966). Some universals of grammar with particular reference to the order of meaningful elements. In Joseph H. Greenberg (ed.), Universals of language, 73-113. Cambridge, MA: MIT Press.

Grice, Martine, \& Michelina Savino (2003). Map tasks in Italian: Asking questions about given, accessible and new information. Catalan Journal of Linguistics 2:153-80.

Gussenhoven, Carlos (2016). Foundations of intonational meaning: Anatomical and physiological factors. Topics in Cognitive Science 8(2):425-34.

Hale, Ken (1983). Warlpiri and the grammar of non-configurational languages. Natural Language \& Linguistic Theory 1(1):5-47.

Halliday, M. A. K., \& Ruqaiya Hasan (1976). Cohesion in English. London: Longman.

't Hart, Johan; René Collier; \& Antonie Cohen (1990). A perceptual study of intonation: An experimental-phonetic approach to speech melody. Cambridge: Cambridge University Press.

Haspelmath, Martin (2010). Comparative concepts and descriptive categories in crosslinguistic studies. Language 86(3):663-87.

Hayashi, Makoto; Geoffrey Raymond; \& Jack Sidnell (2013). Conversational repair and human understanding: An introduction. In Makoto Hayashi, Geoffrey Raymond, \& Jack Sidnell (eds.), Conversational repair and human understanding, 1-40. Cambridge: Cambridge University Press. 


\section{GIOVANNI ROSSI}

Hepburn, Alexa, \& Galina B. Bolden (2013). The conversation analytic approach to transcription. In Jack Sidnell \& Tanya Stivers (eds.), Handbook of conversation analysis, 57-76. Malden, MA: Wiley-Blackwell.

Heritage, John (1984). A change-of-state token and aspects of its sequential placement. In J. Maxwell Atkinson \& John Heritage (eds.), Structures of social action: Studies in conversation analysis, 299-345. Cambridge: Cambridge University Press.

Hirst, Daniel, \& Albert Di Cristo (eds.) (1998). Intonation systems: A survey of twenty languages. Cambridge: Cambridge University Press.

Jefferson, Gail (1972). Side sequences. In David N. Sudnow (ed.), Studies in social interaction, 294338. New York: The Free Press.

Johnstone, Barbara (ed.) (1994). Repetition in discourse: Interdisciplinary perspectives, vol. 1. Norwood, NJ: Ablex.

Keenan, Elinor (1977). Making it last: Repetition in children's discourse. In Susan M. Ervin-Tripp \& Claudia Mitchell-Kernan (eds.), Child discourse, 125-38. New York: Academic Press.

Kelly, John, \& John Local (1989). Doing phonology. Manchester: Manchester University Press.

Kendrick, Kobin H. (2015). Other-initiated repair in English. Open Linguistics 1:164-90.

Koshik, Irene (2002). Designedly incomplete utterances: A pedagogical practice for eliciting knowledge displays in error correction sequences. Research on Language \& Social Interaction 35 (3):277-309.

Ladd, D. Robert (2008). Intonational phonology. 2nd edn. Cambridge: Cambridge University Press.

Lee, Seung-Hee (2016). Information and affiliation: Disconfirming responses to polar questions and what follows in third position. Journal of Pragmatics 100:59-72.

Lerner, Gene H.; Galina B. Bolden; Alexa Hepburn; \& Jenny Mandelbaum (2012). Reference recalibration repairs: Adjusting the precision of formulations for the task at hand. Research on Language \& Social Interaction 45(2):191-212.

Local, John (2007). Phonetic detail and the organisation of talk-in-interaction. In Proceedings of the 16th International Congress of Phonetic Sciences: ICPhS XVI, 1-10. Saarbrücken: Universität des Saarlandes.

_, \& Gareth Walker (2005). Methodological imperatives for investigating the phonetic organization and phonological structures of spontaneous speech. Phonetica 62(2-4):120-30.

Nolan, Francis (2006). Intonation. In Bas Aarts \& April McMahon (eds.), The handbook of English linguistics, 433-55. Malden, MA: Blackwell.

Norrick, Neal R. (1987). Functions of repetition in conversation. Text 7(3):245-64.

O'Connor, J. D., \& G. F. Arnold (1973). Intonation of colloquial English. 2nd edn. London: Longman.

Ogden, Richard (2006). Phonetics and social action in agreements and disagreements. Journal of Pragmatics 38(10):1752-75.

Ohala, John J. (1983). Cross-language use of pitch: An ethological view. Phonetica 40(1):1-18.

Persson, Rasmus (2015). Registering and repair-initiating repeats in French talk-in-interaction. Discourse Studies 17(5):583-608.

(2017). Fill-in-the-blank questions in interaction: Incomplete utterances as a resource for doing inquiries. Research on Language and Social Interaction 50(3):227-48.

Pierrehumbert, Janet B. (1980). The phonology and phonetics of English intonation. Cambridge, MA: MIT dissertation.

— \& Julia Hirschberg (1990). The meaning of intonational contours in the interpretation of discourse. In Philip R. Cohen, Jerry L. Morgan, \& Martha E. Pollack (eds.), Intentions in communication, 271-311. Cambridge, MA: MIT Press.

Pillet-Shore, Danielle (2012). Greeting: Displaying stance through prosodic recipient design. Research on Language and Social Interaction 45(4):375-98.

Quirk, Randolph; Sidney Greenbaum; Geoffrey N. Leech; \& Jan Svartvik (1972). A grammar of contemporary English. London: Longman. 


\section{OTHER-REPETITION IN CONVERSATION ACROSS LANGUAGES}

Raymond, Geoffrey (2003). Grammar and social organization: Yes/no interrogatives and the structure of responding. American Sociological Review 68(6):939-67.

Robinson, Jeffrey D., \& Heidi Kevoe-Feldman (2010). Using full repeats to initiate repair on others' questions. Research on Language \& Social Interaction 43(3):232-59.

Rossi, Giovanni (2015). Other-initiated repair in Italian. Open Linguistics 1(1):256-82.

Sacks, Harvey; Emanuel A. Schegloff; \& Gail Jefferson (1974). A simplest systematics for the organization of turn-taking for conversation. Language 50(4):696-735.

Savino, Michelina, \& Martine Grice (2011). The perception of negative bias in Bari Italian questions. In Sónia Frota, Gorka Elordieta, \& Pilar Prieto (eds.), Prosodic categories: Production, perception, and comprehension, 187-206. Dordrecht: Springer.

Schegloff, Emanuel A. (1996). Confirming allusions: Toward an empirical account of action. The American Journal of Sociology 102(1):161-216.

(1997). Practices and actions: Boundary cases of other-initiated repair. Discourse Processes 23(3):499-546.

(2004). On dispensability. Research on Language \& Social Interaction 37(2):95-149.

(2007). Sequence organization in interaction: A primer in conversation analysis, vol. 1. Cambridge: Cambridge University Press.

; Gail Jefferson; \& Harvey Sacks (1977). The preference for self-correction in the organization of repair in conversation. Language 53(2):361-82.

_ \& Harvey Sacks (1973). Opening up closings. Semiotica 8(4):289-327.

Selting, Margret (1996). Prosody as an activity-type distinctive cue in conversation: The case of socalled 'astonished' questions in repair initiation. In Elizabeth Couper-Kuhlen \& Margret Selting (eds.), Prosody in conversation: Interactional studies, 231-70. Cambridge: Cambridge University Press.

Sidnell, Jack. (2009). Comparative perspectives in conversation analysis. In Jack Sidnell (ed.), Conversation analysis: Comparative perspectives, 3-27. Cambridge: Cambridge University Press.

- (2010). Conversation analysis. In Nancy H. Hornberger \& Sandra Lee McKay (eds.), Sociolinguistics and language education, 492-527. Bristol: Multilingual Matters.

(2014). The architecture of intersubjectivity revisited. In N. J. Enfield, Paul Kockelman, \& Jack Sidnell (eds.), The Cambridge handbook of linguistic anthropology, 364-99. Cambridge: Cambridge University Press.

Silverman, Kim; Mary Beckman; John Pitrelli; Mari Ostendorf; Colin Wightman; Patti Price; Janet Pierrehumbert; \& Julia Hirschberg (1992). ToBI: A standard for labeling English prosody. In Proceedings of the 2nd International Conference on Spoken Language Processing [ICSLP 1992], 867-70.

Sorjonen, Marja-Leena (1996). On repeats and responses in Finnish conversations. In Elinor Ochs, Emanuel A. Schegloff, \& Sandra A. Thompson (eds.), Interaction and grammar, 277-327. Cambridge: Cambridge University Press.

(2001). Responding in conversation: A study of response particles in Finnish. Amsterdam: John Benjamins.

Stivers, Tanya; N. J. Enfield; Penelope Brown; Christina Englert; Makoto Hayashi, Trine Heinemann; Gertie Hoymann; Federico Rossano; Jan Peter de Ruiter; Kyung-Eun Yoon; \& Stephen C. Levinson (2009). Universals and cultural variation in turn-taking in conversation. Proceedings of the National Academy of Sciences 106(26):10587-92.

Svennevig, Jan (2008). Trying the easiest solution first in other-initiation of repair. Journal of Pragmatics 40(2):333-48.

Szczepek Reed, Beatrice, \& Rasmus Persson (2016). How speakers of different languages extend their turns: Word linking and glottalization in French and German. Research on Language and Social Interaction 49(2):128-47.

Tannen, Deborah (1989). Talking voices: Repetition, dialogue, and imagery in conversational discourse. Cambridge: Cambridge University Press. 


\section{GIOVANNI ROSSI}

Tarplee, Clare (1996). Working on young children's utterances: Prosodic aspects of repetition during picture labelling. In Elizabeth Couper-Kuhlen \& Margret Selting (eds.), Prosody in conversation: Interactional studies, 406-35. Cambridge: Cambridge University Press.

Walker, Gareth (2013). Phonetics and prosody in conversation. In Jack Sidnell \& Tanya Stivers (eds.), Handbook of conversation analysis, 455-74. Malden, MA: Wiley-Blackwell.

Ward, Gregory, \& Julia Hirschberg (1985). Implicating uncertainty: The pragmatics of fall-rise intonation. Language 61(4):747-76.

Wilkinson, Sue, \& Celia Kitzinger (2006). Surprise as an interactional achievement: Reaction tokens in conversation. Social Psychology Quarterly 69(2):150-82.

Wu, Ruey-Jiuan Regina (2006). Initiating repair and beyond: The use of two repeat-formatted repair initiations in Mandarin conversation. Discourse Processes 41(1):67-109.

(Received 20 July 2018; accepted 7 August 2019; final revision received 3 September 2019)

Address for correspondence:

Giovanni Rossi

Department of Sociology

University of California, Los Angeles

375 Portola Plaza, 264 Haines Hall

Los Angeles, CA 90095-1551, USA

rossi@soc.ucla.edu 